\title{
GRAVITATIONAL PATTERN OF THE Y-BEARING HUMAN SPERMATOZOA IN DENSITY GRADIENT CENTRIFUGATION
}

\author{
W. ROHDE, T. PORSTMANN, S. PREHN AND G. DÖRNER \\ Institute of Experimental Endocrinology, Institute of Pathology, \\ Institute of Biological and Physiological Chemistry, \\ Humboldt-University, 104 Berlin, GDR
}

(Received 17th September 1974)

Numerous attempts have been made to separate the $\mathrm{X}$ - and $\mathrm{Y}$-bearing spermatozoa of mammals (Kiddy \& Hafs, 1971). In our initial studies of the progressive sperm motility in cervical mucus of women, we found a fraction that was rich in Y-bearing spermatozoa in the frontal zone of sperm migration (Rohde, Zillmann, Porstmann \& Dörner, 1972; Rohde, Porstmann \& Dörner, 1973). Using an in-vitro penetration test, Kaiser, Broer, Citoler \& Leister (1974) reported similar results. Ericsson, Langerin \& Nishino (1973) reported the isolation of fractions rich in Y-bearing human spermatozoa using the progressive sperm motility in bovine serum albumin solutions of various densities. The present study reports the use of density gradient centrifugation with a discontinuous sucrose gradient, to demonstrate that human spermatozoa tend to separate into populations with distinct percentages of $\mathrm{X}$ - and $\mathrm{Y}$ bearing spermatozoa.

Freshly ejaculated 'normal' semen samples, which were allowed to liquefy for $15 \mathrm{~min}$ at $37^{\circ} \mathrm{C}$, were freed from coarse aggregated cell material by simple sedimentation, washed six times with modified $\mathrm{Ca}^{2+}$-free Ringer solution and then suspended in $0.5 \mathrm{ml}$ of this solution. The discontinuous sucrose gradients were prepared by layering equal volumes of a 60,50, 40 and $30 \%$ sucrose solution (in $\mathrm{Ca}^{2+}$-free Ringer) into cellulose acetate tubes to which $0.5 \mathrm{ml}$ of the washed semen samples were then applied. The centrifugations were carried out in a Beckman ultracentrifuge, Model L 2-65, for 30 or 60 min at $4^{\circ} \mathrm{C}$ and at $12,000,26,400,49,600,63,600$ or $77,500 \mathrm{~g}$. The centrifuged tubes were photographed by indirect illumination and the densitometer tracing was made from the photographic negative. The tubes were fractionated by aspiration of the different banding regions, using a special glass pipette with a finely drawn outlet. The fractions were washed with $\mathrm{Ca}^{2+}$-free $\mathrm{Ringer}$ and concentrated by centrifugation. The sedimented material was suspended in drops of $0.15 \mathrm{M}-\mathrm{NaCl}$, and slides stained with quinacrine dihydrochloride were made. These were analysed by fluorescence microscopy as described by Rohde, Porstmann, Zillmann \& Dörner (1972). The first 1500 morphologically 'intact' spermatozoa were analysed in each fraction and in smears of the corresponding semen samples. In Fractions 1 and 2, only 100 to 500 cells and 500 to 1500 cells, respectively, were counted due to the lack of material.

A characteristic pattern of density gradient centrifugation of human sperma- 
tozoa in a discontinuous sucrose gradient is shown in Text-fig. 1. In all instances, four bands of differing density, numbered as Fractions 1 to 4 from low density to high density, were observed. The spermatozoa which remained as a pellet at the bottom of the tube was numbered Fraction 5. The preliminary results of ten experiments are shown in Table 1. In contrast to the report of Ericsson et al. (1973), we were not able to identify approximately $50 \%$ of the spermatozoa as Y-bearing in the control semen samples with our method and the counts of spermatozoa containing fluorescent bodies differed from 25 to $43 \%$ within

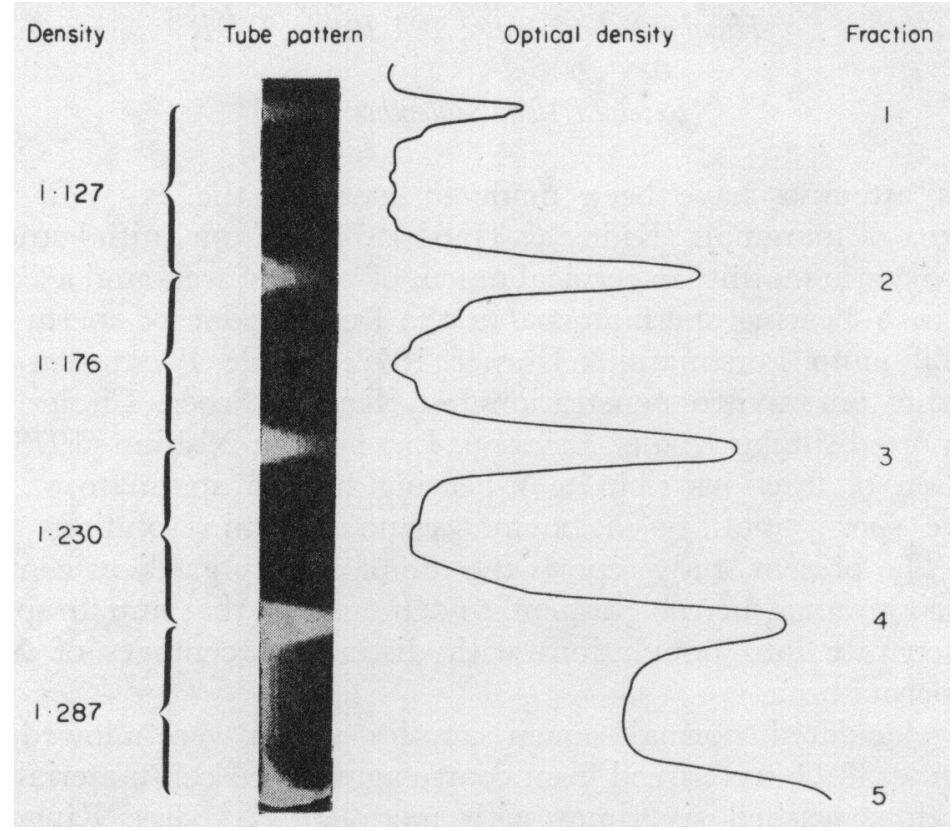

TEXT-FIG. 1. Density gradient centrifugation of human spermatozoa. Densitometric and photographic pattern of spermatozoa centrifuged at $26,400 \mathrm{~g}$ in a discontinuous sucrose gradient. The apparent densitometric band at the bottom of the tube is partly caused by light reflection and is a rough approximation of the sperm concentration in this part of the tube.

donors. Although this fact would appear to cast doubt on the accuracy of our data, the results of the two counters (T.P. and W.R.) were compared for each Fraction and the control semen sample and were found to be statistically consistent. An analysis of variance indicated significant differences in the percentage of Y-bearing spermatozoa between the Fractions and the corresponding control semen samples in all experiments $(P<0.01)$. A clear tendency to higher percentages of $\mathrm{Y}$-bearing spermatozoa was demonstrable for Fractions 1 and 2 which had lower densities.

The possibility that sucrose concentrations affect the apparent number of fluorescent bodies was excluded by appropriate controls (Table 2 ). Spermatozoa were exposed to various concentrations of sucrose with and without centrifugation $(77,500 \mathrm{~g})$ and were treated in the same way as those in the experiments. No significant change in the number of fluorescent bodies was found. 


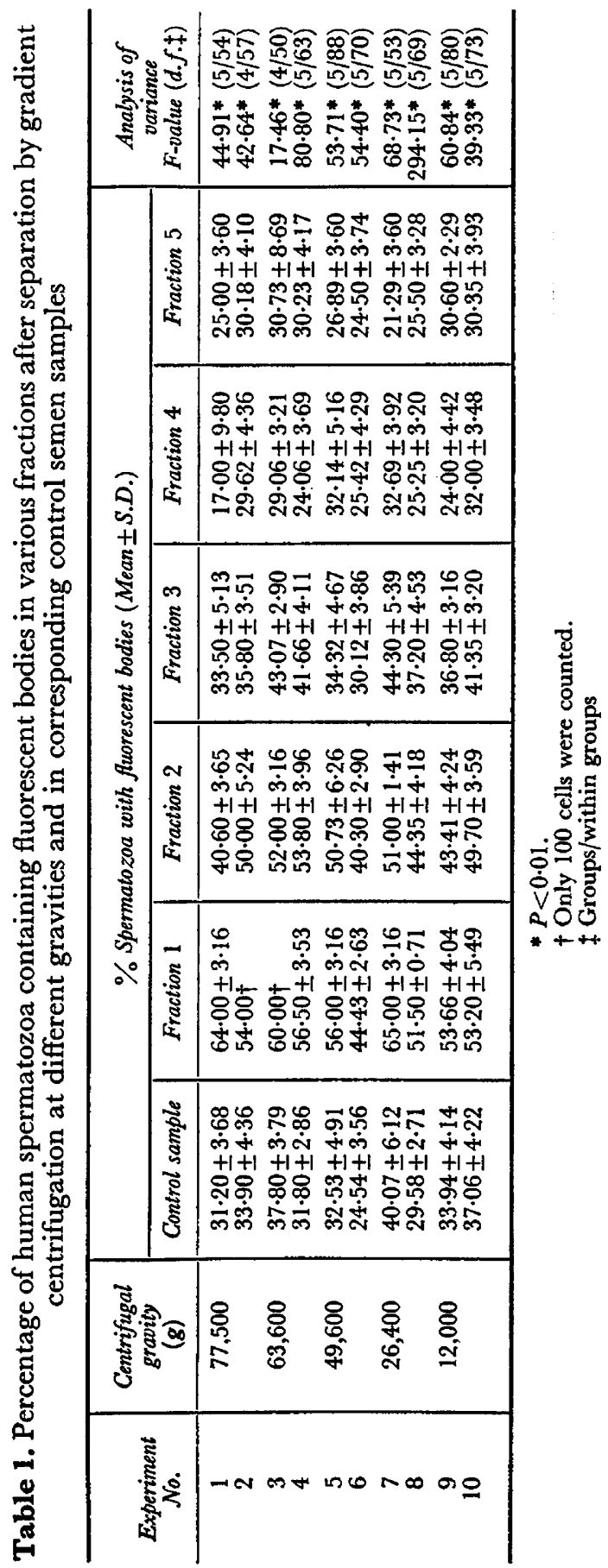


Table 2. Percentage of human spermatozoa containing fluorescent bodies in a control semen sample before and after exposure to the various conditions of the experiment

\begin{tabular}{|c|c|c|c|c|c|c|}
\hline & \multicolumn{6}{|c|}{$\%$ Spermatozoa with fluorescent bodies (Mean \pm S.D.)* } \\
\hline & \multicolumn{4}{|c|}{ Concentration of sucrose $\dagger$} & \multirow{2}{*}{$\begin{array}{c}\text { Washed } \\
\text { six times with } \\
\text { Ca } a^{2+}-\text { free } \\
\text { Ringer }\end{array}$} & \multirow{2}{*}{$\begin{array}{l}\text { Untreated } \\
\text { semen } \\
\text { sample }\end{array}$} \\
\hline & $30 \%$ & $40 \%$ & $50 \%$ & $60 \%$ & & \\
\hline $\begin{array}{l}\text { Incubation for } \\
60 \mathrm{~min} \text { at } 4^{\circ} \mathrm{C}\end{array}$ & $\begin{array}{c}41 \cdot 6 \\
\pm 2 \cdot 99\end{array}$ & $\begin{array}{c}42 \cdot 5 \\
\pm 4 \cdot 81\end{array}$ & $\begin{array}{c}42 \cdot 2 \\
\pm 3 \cdot 49\end{array}$ & $\begin{array}{c}42 \cdot 1 \\
\pm 3 \cdot 51\end{array}$ & $\begin{array}{c}42 \cdot 3 \\
\pm 2 \cdot 50\end{array}$ & $\begin{array}{c}43 \cdot 1 \\
\pm 3 \cdot 04\end{array}$ \\
\hline $\begin{array}{l}\text { Gentrifugation at } \\
77,500 \text { g for } 60 \\
\text { min at } 4^{\circ} \mathrm{C} \text {, }\end{array}$ & $\begin{array}{c}42 \cdot 1 \\
\pm 2 \cdot 13\end{array}$ & $\begin{array}{c}42.1 \\
\pm 3.03\end{array}$ & $\begin{array}{c}42 \cdot 6 \\
\pm 4 \cdot 93\end{array}$ & $\begin{array}{l}42 \cdot 5 \\
\pm 3 \cdot 75\end{array}$ & - & - \\
\hline
\end{tabular}

* A total of 1000 successive morphologically intact cells were counted in each sample.

$\dagger$ After washing with $\mathrm{Ca}^{2+}$-free Ringer.

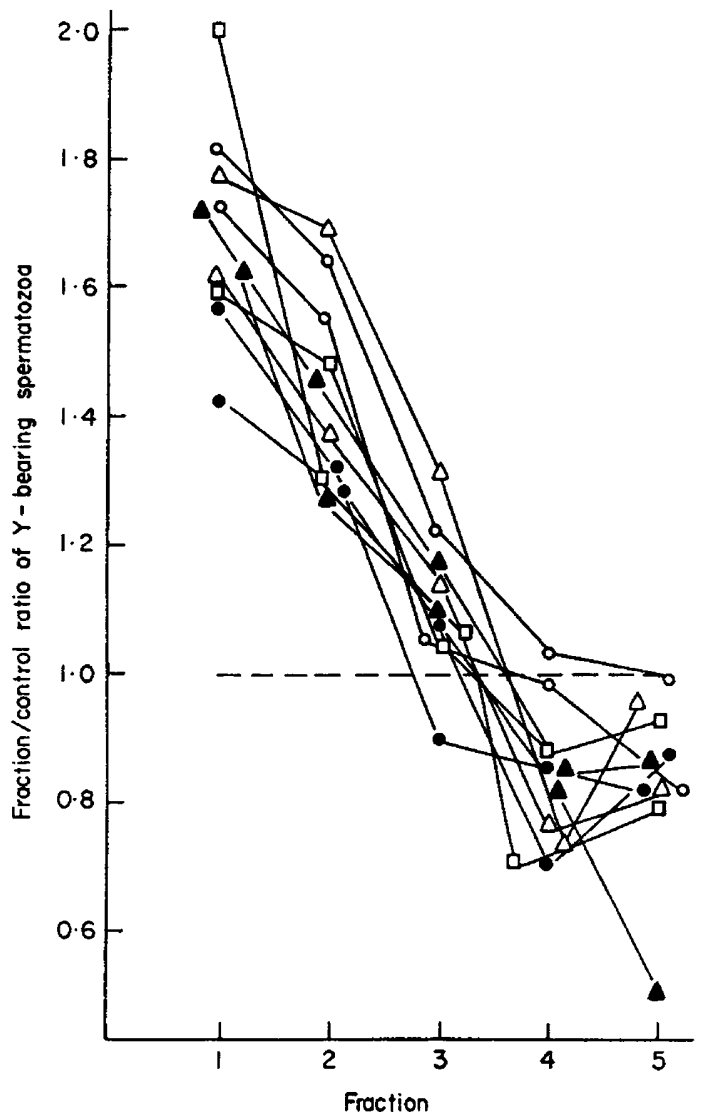

TEXT-FIG. 2. Distribution of human spermatozoa containing fluorescent bodies in the different fractions obtained after density gradient centrifugation at various gravities. The 'fraction/control-ratio' of Y-bearing spermatozoa was calculated from the $\% \mathrm{Y}$ bearing spermatozoa in the different fractions divided by the $\%$ Y-bearing spermatozoa in the corresponding untreated semen sample. $0,12,000 \mathrm{~g} ; \mathbf{\Lambda}, 26,400 \mathrm{~g} ; 0,49,600 \mathrm{~g}$; $\Delta, 63,600 \mathrm{~g} ; \square, 77,500 \mathrm{~g}$. 
The gravitational patterns of Y-bearing spermatozoa were reproducible at different rotor speeds and at gravities between 77,500 and 12,000 $\mathrm{g}$ (Text-fig. 2). At the lower gravities, an increase of cell material in Fractions 2, 3 and 4 and a decrease of cell material in Fraction 5 were deduced from the densitometer tracings. No data indicating the viability of spermatozoa were collected in this study. It may be presumed, however, that many of the spermatozoa were dead as a result of the treatment. The morphological characteristics in the different ractions and other details will be described elsewhere.

Our results support the findings of authors who observed apparent changes in sex ratio after insemination of bovine or rabbit spermatozoa separated by centrifugation (Lindahl, 1958; Stambaugh \& Buckley, 1971). Other investigators have not been able to demonstrate any deviation of sex ratio (Lush, 1925; Lovelock, 1960; Benedict, Schumaker \& Davies, 1967; Beatty, 1969). These preliminary results need to be confirmed using parameters other than the fluorescent body.

\section{REFERENCES}

BeAtTy, R. A. (1969) Genetic content and buoyant density of rabbit spermatozoa. 7. Reprod. Fert. 19, 379-384.

Benedict, R. C., Schumaker, V. N. \& Davies, R. E. (1967) The buoyant density of bovine and rabbit spermatozoa. F. Reprod. Fert. 13, 237-249.

Ericsson, R. J., Langevin, C. N. \& Nishino, M. (1973) Isolation of fractions rich in human Y sperm. Nature, Lond. 246, 421-424.

KAISER, R., BrokR, K. H., Gitol.er, P. \& LeIster, B. (1974) Nachweis Y-Ghromatin-positiver Spermien im Zervixsekret beim In-vitro-Penetrationstest. Geburtsh. Frauenheilk. 34, 426-430.

KIDDy, C. A. \& HAfs, H. D. (Eds.) (1971) Sex Ratio at Birth-Prospects for Control. American Society of Animal Science.

LindaHL, P. E. (1958) Separation of bull spermatozoa carrying X- and Y-chromosomes by counter streaming centrifugation. Nature, Lond. 181, 784.

Lovelock, J. E. (1960) Comment on the possibility of controlling sex ratio and development. In Sex Differentiation and Development. Mem. Soc. Endocr. 7, 113-114.

Lush, J. L. (1925) The possibility of sex control by artificial insemination with centrifuged spermatozoa. 7. agric. Res. 30, 893.

Rohde, W., Porstmann, T. \& Dörner, G. (1973) Migration of Y-bearing human spermatozoa in cervical mucus. F. Reprod. Fert. 33, 167-169.

Rohde, W., Porstmann, T., Zillmann, R. \& Dörner, G. (1972) Zum fluoreszenzmikroskopischen Nachweis des Y-Chromosoms in unbehandelten und trypsinbehandelten menschlichen Spermien. Acta biol. med. germ. 28, 189-192.

Rohde, W., Zillmann, R., Porstmann, T. \& Dörner, G. (1972) Prenatal determination of genetic sex and partial separation of X-and Y-bearing spermatozoa in the human. In Int. Symp. on Differentiation and Neuroendocrine Regulation in the Hypothalamo-Hypophyseal Gonadal-System, Berlin, Abstract No. 4.

Stambaugh, R. \& Buckley, J. (1971) Association of the lactic dehydrogenase $\mathrm{X}_{4}$ isozyme with maleproducing rabbit spermatozoa. F. Reprod. Fert. 25, 275-278. 